\title{
Análisis de efectos tributarios en las Mipymes. Una perspectiva e impacto del contenido de la Ley de simplificación y progresividad tributaria 2020.
}

Analysis of tax effects in MSMEs. A critical perspective of the content of the 2020 Tax Simplification and Progressivity Law.

Edison Becerra Molina. ${ }^{1}$, Oscar Calle Masache. ${ }^{2}$, Tito Banegas Peña. ${ }^{3}$ \& Héctor Espinoza Pillaga. ${ }^{4}$

Recibido: 14-03-2020 / Revisado: 19-04-2020 /Aceptado: 08-05-2020/ Publicado: 05-06-2020

\begin{abstract}
.
DOI: $\underline{\text { https://doi.org/10.33262/concienciadigital.v3i2.2.1249 }}$

This article is based on the tax obligations that the taxpayers of MSMEs have, the new tax regime for micro-businesses, created in the Organic Law of Tax Simplification (2019), has its rules for its application. The Internal Revenue Service (SRI) issued a resolution on the cadastre and obligations of these taxpayers, the last one, this past May 22,2020 , where it will proceed to comply with a transitional provision of the law that set a deadline 20 days, from the effective date of the rule, for the SRI to carry out an ex officio update of the Single Taxpayer Registry (RUC) to micro-companies, according to the regulations of the Production Code, micro-businesses are those businesses with sales or gross income annual equal to or less than USD 300,000, the tax administration also includes small merchants, entrepreneurs, in addition to natural persons obliged or not to keep accounting and companies that have had gross income in the immediately preceding year equal to or less than the aforementioned amount, the purpose of this research is to determine what would be the behavior of taxpayers, since they cease to be age Before withholding, and the declarations become semiannual, what will be the impact, since they have to accumulate semi-annually those resources that they will need to cover the semi-annual VAT obligation, the repercussion deepens even more, how much they have to pay on the total gross sales of $2 \%$ imposed on them, without considering the result of the fiscal year. The methodology used in the
\end{abstract}

\footnotetext{
${ }^{1}$ Universidad Católica de Cuenca, Cuenca, Ecuador, jbecerram@ucacue.edu.ec

${ }^{2}$ Universidad Católica de Cuenca, Cuenca, Ecuador, ocalle@ucacue.edu.ec

${ }^{3}$ Universidad Católica de Cuenca, Cuenca, Ecuador, tbanegasp@ucacue.edu.ec

${ }^{4}$ Universidad Católica de Cuenca, Cuenca, Ecuador, hespinozap@ucacue.edu.ec
} 
research was descriptive in the field, based on the bibliographic and documentary review, and the survey technique and the questionnaire instrument, which allowed to review, analyze, diagnose and point out issues related to the application of the law. To calculate the sample size, an objective population of 100 Accountants and Auditors has been used, members of the National Union of Colleges of Accountants of Ecuador (UNACCE), who are labor-related, either in a dependency relationship or by professional services with MSMEs Corresponding to a sample of $n=79$ questionnaires, the results undoubtedly show that these taxes would mean a severe blow to the MSMEs economy, especially for microentrepreneurs, small entrepreneurs, and entrepreneurs.

Keywords: Taxes, mipymes, taxpayers, obligations.

\section{Resumen.}

El presente artículo está basado en las obligaciones tributarias que tienen los contribuyentes de las Mipymes, el nuevo régimen impositivo para las microempresas, creado en la Ley Orgánica de Simplificación Tributaria (2019), cuenta con sus reglas para su aplicación. El Servicio de Rentas Internas -SRI (2020), emitió una resolución sobre el catastro y obligaciones de estos sujetos pasivos, el pasado 22 de mayo del 2020 , en donde se procederá a dar cumplimiento a una disposición transitoria de la ley que fijó un plazo de 20 días, desde la vigencia de la norma, para que el SRI formalizara una actualización de oficio del Registro Único de Contribuyentes (RUC) a las microempresas, según el reglamento del Código de la Producción, son microempresas aquellos negocios con ventas o ingresos brutos anuales iguales o menores a USD $\$ 300.000,00$, la administración tributaria incluye también a los pequeños comerciantes, emprendedores, además las personas naturales obligadas o no a llevar contabilidad y las sociedades que hayan tenido ingresos brutos al año inmediato anterior iguales o menores al monto anteriormente citado, el objeto de la presente investigación estriba en determinar cuál sería el comportamiento de los contribuyentes, toda vez que dejan de ser agentes de retención, y las declaraciones pasan a ser semestrales, cuál será el impacto, por cuanto tienen que tienen que acumular semestralmente aquellos recursos que necesitaran para cubrir la obligación semestral del IVA, la repercusión se ahonda más todavía, cuanto tengan que tributar sobre el total de las ventas brutas el $2 \%$ que les imponen, sin considerar el resultado del ejercicio fiscal. La metodología utilizada en la investigación fue de campo de carácter descriptivo, en base a la revisión bibliográfica y documental, y la técnica de la encuesta y el instrumento el cuestionario, que permitió revisar, analizar, diagnosticar y puntualizar temas referentes a la aplicación de la ley. Para el cálculo del tamaño de la muestra se ha utilizado una población objetiva de 100 Contadores y Auditores, agremiados en la Unión Nacional de Colegios de Contadores del Ecuador (UNACCE), vinculados laboralmente ya sea con relación de dependencia o por servicios profesionales con las Mipymes, correspondiendo una muestra de $n=79$ cuestionarios, los resultados arrojan sin duda que estos tributos significarían un golpe 
duro a la economía de las Mipymes, especialmente de los microempresarios, pequeños empresarios y emprendedores.

Palabras claves: Tributos, mipymes, contribuyentes, obligaciones.

\section{Introducción.}

Los impuestos constituyen una parte sustancial del presupuesto general del Estado. Sin embargo, es por ello que los ingresos públicos, contribución, servicios públicos, donaciones multas entre otros, de igual manera de los ingresos que perciben los ciudadanos algunos causan impuestos lo que se convierte en tributo que el Estado percibe con el fin de incrementar recursos para las arcas fiscales que luego deben ser revertidos en beneficio del país. El año pasado, el Fondo Monetario Internacional (FMI) esperaba que el país recaude USD \$ 14.378 millones. El Servicio de Rentas Internas recaudó USD \$ 14.269 millones: es decir llegó al 99,2\% con relación a la meta. Según el SRI, el total recaudado en 2019, es la cifra más alta en la historia de la institución. Para el año en curso, el compromiso con el FMI es que el país genere ingresos tributarios por USD \$ 14.772 millones. El Estado espera recaudar unos USD \$ 540 millones adicionales en 2020 con la Ley de Simplificación y Progresividad Tributaria que fue aprobada el 31 de diciembre de 2019.

En este orden de análisis, en enero de 2020, el Servicio de Rentas Internas, recaudó USD \$ 1.367 millones, un 1,1\% más que los USD \$ 1.352 millones recaudados en enero del año pasado. La administración pública recaudó, en enero, USD \$14,8 millones más que en el mismo mes del año pasado, según el reporte, consultado la recaudación, el 31 de enero. El Impuesto al Valor Agregado (IVA), que es el tributo con más peso en la recaudación total, significó USD \$ 712,8 millones. Esto representa un crecimiento de 2,5\% con respecto a enero del año pasado. Por el Impuesto a la Renta, el SRI recaudó USD \$ 403,7 millones. Por lo tanto, la recaudación de este tributo creció 1,3\% en 2020. De igual manera, la recaudación del Impuesto a la Salida de Divisas (ISD) subió 10,6\%, al pasar de USD 106,9 millones a USD \$ 118,2 millones. La recaudación del Impuesto a los Consumos Especiales (ICE) alcanzó USD \$ 89,8 millones, un 1,8\% más que el año pasado. Entre el Impuesto a la Renta, el IVA y el ISD sumaron el 90,3\% de la recaudación de enero del presente año.

En consecuencia, considerando esta información el grupo investigador procedió al análisis de la ley orgánica de simplificación y progresividad tributaria, como consecuencia de determinar el impacto que tendrá la misma en las Mipymes, La norma señala que los contribuyentes formarán parte mientras dure su condición de microempresa, pequeñas empresas o emprendimientos, este tiempo no podrá ser mayor a cinco ejercicios fiscales. Las aplicaciones de los cuestionarios realizados a los actores dividen las opiniones de analistas y emprendedores. Así como hay quienes creen que el mecanismo facilita el cumplimiento de las obligaciones tributarias, otros sostuvieron que habrá obstáculos, por cuanto advierten que el esquema planteado para calcular el impuesto a la renta, que no contempla costos ni gastos, 
ISSN: 2600-5859

podría resultar perjudicial para aquellos negocios que generan altos egresos por su operación y que anteriormente podían deducir del impuesto. Por consiguiente, se cuestiona que se tribute el $2 \%$ sobre los ingresos brutos cuando se desconoce si al final del ejercicio habrá déficit o excedentes, en una Mipyme, la mano de obra es de los costos más altos. Para otros actores creen que el régimen impositivo contiene facilidades que incentivarán la formalización de las actividades económicas a las que se dedican los microempresarios.

\section{Metodologia.}

El tipo de investigación corresponde al nivel descriptivo, al respecto según, Arias (2016), manifiesta que: consiste en la caracterización de un hecho, fenómeno, individúo o grupo, con el fin de conocer su estructura o comportamiento. Los resultados de este tipo de investigación se ubican en un nivel intermedio en cuanto a la profundidad de los conocimientos se refiere, ligada a la investigación de campo, referente a este aspecto Arias (2016), revela que es aquella que consiste en la recolección de datos directamente de los sujetos investigados, o de la realidad donde ocurren los hechos (datos primarios), sin manipular o controlar variable alguna, es decir el investigador obtiene la investigación pero no altera las condiciones existentes. De allí su carácter de investigación no experimental.

Para la recolección de datos la técnica utilizada en la presente investigación fue la encuesta y el instrumento el cuestionario, por su parte, Hernández Sampieri, R., Fernández-Collado, C., \& Baptista Lucio, P. (2010) sostiene que es: aquella que busca especificar propiedades, características y rasgos importantes de cualquier fenómeno que se analice. Describe tendencias de un grupo o población.

Para la elaboración del Proyecto de una población objetiva de 100 Contadores y Auditores de la Unión de Colegios de Contadores del Ecuador (UNACE), vinculados laboralmente a las Mipymes, correspondiendo una muestra de $n=79$ cuestionarios, mismas que fueron validadas mediante el alfa de Cronbach, al respecto Bernal (2006), afirma que la confiabilidad es la consistencia que tiene el instrumento y que permite evaluar, mediante una prueba piloto, verificando así su veracidad, el cual es empleado cuando la herramienta comprende ítems con alternativas de respuestas múltiples.

Para el caso de los cuestionarios a los profesionales Contadores, se aplicó un cuestionario digital, establecidas dentro de los cuestionarios preguntas tipo Likert, en este sentido Cañadas y Sánchez (1998), la escala de Likert es un método de medición utilizado por los investigadores con el objetivo de evaluar la opinión y actitudes de las personas.

Cabe destacar que se utilizó la herramienta Google formularios enviado el link a los correos electrónicos de los encuestados, y persuadiendo igualmente, en algunos casos, por vía telefónica a que colaboraran con el llenado del cuestionario. Una vez obtenida la información 
de estos apartados se exportaron al SPSS, versión 26.0, para el respectivo procesamiento y análisis.

\section{Fundamentación Teórica}

Los impuestos constituyen recursos fundamentales para el financiamiento del gasto público, para tal fin los gobiernos definan una política tributaria en cada uno de los países, de allí que es importante determinar con claridad el tamaño del Estado y las necesidades que tiene el mismo en materia de salud, educación, vialidad, servicios básicos, vialidad, y demás actividades sociales, entre otros, con el objeto de evitar que el exceso de gasto público y la corrupción afecte al crecimiento económico y permita que los beneficios en el área social puedan verse incrementados. Por su parte, Fleiner, citado por el jurista paraguayo Mersan (1997), en su obra derecho tributario, define al tributo como: "...prestaciones pecuniarias que el Estado u otros organismos de Derecho Público exigen en forma unilateral a los ciudadanos para cubrir las necesidades económicas.". Concluye el ilustre autor afirmando que el tributo es toda prestación pecuniaria debida al Estado u otros organismos de Derecho Público, por los sujetos obligados en virtud de una norma legalmente establecida, para satisfacer los requerimientos del desarrollo nacional.

Según, el Art. 6 del Código Tributario del Estado Ecuatoriano (2020), con respecto a los fines de los tributos, manifiesta: que "los tributos, además de ser medios para recaudar ingresos públicos, servirán como instrumento de política económica general, estimulando la inversión, la reinversión, el ahorro y su destino hacia los fines productivos y de desarrollo nacional; atenderán a las exigencias de estabilidad y progreso sociales y procurarán una mejor distribución de la renta nacional”, (p.2).

Así mismo, el Art. 285 de la Constitución de la República del Ecuador (2008), sostiene que la política fiscal tendrá como objetivos específicos: "1. El financiamiento de servicios, inversión y bienes públicos.2. La redistribución del ingreso por medio de transferencias, tributos y subsidios adecuados”, (p.140).

3. La generación de incentivos para la inversión en los diferentes sectores de la economía y para la producción de bienes y servicios, socialmente deseables y ambientalmente aceptables. De igual forma, el Art. 300 de la Constitución de la República del Ecuador (2008), induce que: "el régimen tributario se regirá por los principios de generalidad, progresividad, eficiencia, simplicidad administrativa, irretroactividad, equidad, transparencia y suficiencia recaudatoria. Se priorizarán los impuestos directos y progresivos”, (p.144).

En torno, a los diversos razonamientos jurídicos y de las mencionadas normas, se puedo instituir que, en el Ecuador, los tributos son aquellas prestaciones de carácter económico demandadas por el Estado a través del Servicio de Rentas Internas (SRI), a los sujetos pasivos o contribuyentes, en mando de una Ley que se regirá por los principios de legalidad, 
ISSN: 2600-5859

generalidad, igualdad, simplicidad, proporcionalidad, progresividad e irretroactividad a fin de cubrir las necesidades del Estado. Es conveniente indicar que el sistema fiscal es el conjunto de leyes, normas y disposiciones acerca de la forma de obtener los ingresos públicos, por lo que, a partir del año 2007, hasta la presente fecha, el gobierno de Ecuador ha realizado varias reformas tributarias que implicaron el aumento por un lado y la disminución por otro lado, ciertos impuestos, cambios a bases imponibles y la creación de nuevos tales como:

Tabla No1. Impuesto a la renta, Rise

\begin{tabular}{|c|c|}
\hline Impuesto a la Renta & RISE \\
\hline Impuesto al Valor Agregado (Operaciones Internas e & Regalías, patentes, utilidades de conservación minera \\
\hline Importaciones) & Tierras Rurales \\
\hline Impuesto a Consumos Especiales (Operaciones Internas e & Contribución para la atención integral del cáncer \\
\hline Importaciones) & Contribución solidaria sobre el patrimonio \\
\hline Impuesto Ambiental Contaminación Vehicular & Contribución solidaria sobre utilidades \\
\hline Impuesto Redimible Botellas Plásticas & Contribución solidaria sobre bienes inmuebles y derechos \\
\hline Impuesto a los Vehículos Motorizados & representativos de capital de propiedad de sociedades no \\
\hline Impuesto a la Salida de Divisas & residentes \\
\hline \multirow[t]{3}{*}{ Impuesto a los Activos en el Exterior } & Contribución solidaria de un día de remuneración \\
\hline & Contribución $2 \%$ IVA \\
\hline & Contribución humanitaria, entre otros. \\
\hline
\end{tabular}

Elaborado por : Grupo de investigación

A partir de la vigencia de la Ley Reformatoria para la Equidad Tributaria en el año 2010 en el Ecuador, se prioriza la necesidad de propender a una mejor distribución de la riqueza y alineado a los Objetivos del Plan Nacional del Buen Vivir Toda una Vida (2017-2021), al Eje 2 "Económica al servicio de la sociedad", donde prevalece el concepto de que es necesario: "implementar políticas fiscales integrales e inclusivas que tiendan a Fortalecer la cultura tributaria basada en el principio de corresponsabilidad fiscal y solidaridad; Mejorando la eficiencia y la progresividad en la recaudación; optimizando la calidad del gasto; Así como perfeccionando el perfil de vencimientos del financiamiento público." (p.65). Por tanto, se toma como una consigna de trabajo direccionar todos los procesos recaudatorios principalmente a los impuestos directos, así como los que se encuentran en tratamiento en la Asamblea nacional el proyecto de Ley orgánica de apoyo humanitario para combatir la crisis sanitaria derivadas del COVID 19, calificado como de urgente en materia económica.

Las modificaciones normativas, tienen como finalidad, gravar los impuestos a los contribuyentes en función de su verdadera capacidad contributiva, permitiendo de esta forma que los valores recaudados vayan en beneficio directo de la población, especialmente de los sectores más vulnerables. 
Según, el objetivo 7 del Plan Nacional de Desarrollo toda una vida PNDTV (2017-2021), se refiere a la necesidad de incentivar una sociedad participativa, con un Estado cercano al servicio de la ciudadanía para lo cual, determina como una de sus políticas, mejorar la calidad de las regulaciones y simplificación de trámites, para aumentar su efectividad en el bienestar económico, político social y cultural.

Así mismo, el sistema tributario es un instrumento fundamental de política económica, que además de proporcionar recursos al Estado, permite estimular la inversión, el ahorro, el empleo y la redistribución de la riqueza; contribuir a la estabilidad económica; regular conductas nocivas para la salud e incentivar actividades que preserven el medio ambiente.

Por otra parte, el número 11 del artículo 3 de la Ley Orgánica para la Optimización y eficiencia de trámites administrativos, establece al principio de simplificación, como uno de los principios que rigen los trámites administrativos, el cual consiste en que los trámites deben ser claros, sencillos, ágiles, racionales, pertinentes, útiles y de fácil entendimiento para los ciudadanos. Asimismo, dispone la necesidad de eliminar toda complejidad innecesaria en los trámites administrativos.

La presente investigación tiene relevancia científica por cuanto permitió realizar un análisis, de la ley orgánica de simplificación y progresividad tributaria (2019), estableció un régimen impositivo, aplicable a los impuestos a la renta, al valor agregado y a los consumos especiales, para microempresas, incluidos emprendedores que cumplan con la condición de microempresas, y de acuerdo a las disposiciones contenidas en esta ley, y que permanecerán en el régimen de microempresas, mientras perdure su condición, sin que en ningún caso su permanencia sea mayor a cinco (5) ejercicios fiscales, posteriormente, se sujetarán al régimen general. Por otra parte, los contribuyentes sujetos al régimen, se sujetarán a este régimen los contribuyentes considerados microempresas, incluidos los emprendedores que cumplan con la condición de microempresas, según lo establecido en el Código Orgánico de la Producción, Comercio e Inversiones y el Reglamento correspondiente, salvo aquellos que se encuentren sujetos al régimen impositivo simplificado.

Del mismo modo, es necesario reconocer al fomento a la actividad de exportación y a la generación de nuevos emprendimientos, según la Ley Orgánica de Emprendimiento e Innovación (2020), que sostiene que es necesario promover el fomento a la actividad de exportación y a la generación de nuevos emprendimientos como ejes transversales de la política pública y económica, puesto que estas actividades permitirán dinamizar la economía y, consecuentemente, conllevarán a la sostenibilidad fiscal a largo plazo.

Según el artículo 97.22, la tarifa del impuesto a la renta, los contribuyentes determinarán el impuesto a la renta aplicando, la tarifa del dos por ciento (2\%) sobre los ingresos brutos del respectivo ejercicio fiscal exclusivamente respecto de aquellos ingresos provenientes de la actividad empresarial. Los ingresos percibidos por las microempresas por fuentes distintas a 
la actividad empresarial se sujetarán al régimen general del impuesto a la renta y será de aplicación obligatoria para las microempresas. Para efectos tributarios la categorización de MIPYMES podrá ser aplicada y controlada por el Servicio de Rentas Internas en función de la información que reposa en sus bases de datos respecto del monto de ingresos, sin perjuicio de la obligación que tengan dichos contribuyentes de registrarse ante el ente rector en los casos que así lo prevea la normativa aplicable.

Para el caso de las pequeñas, medianas y grandes empresas, que tengan ingresos superiores y no hayan sido considerados en el catastro de microempresas, estarán sujetas al régimen general, es decir continuarán realizando las retenciones del impuesto al valor agregado e impuesto a la renta a partir del mes de abril del 2020, que varían para el caso de bienes el $1,75 \%$ y servicios del $2,75 \%$, conforme la tabla de retenciones existentes para el efecto, además tributarán el $25 \%$ sobre las ganancias netas en el ejercicio fiscal.

En lo que respecta, a las micros, medianas y pequeñas empresas (Mipymes), según el Código Orgánico de la Producción, comercio e inversión -COPCI. (2010), son proveedoras de servicios, productos o insumos para otras compañías de amplia cobertura de mercado local, regional, nacional e internacional, Las Mipymes dentro del tejido nacional empresarial aportan de manera significativa al desarrollo productivo y económico del país, de sus beneficios líquidos, aportan con el pago de tributos al erario nacional.

Así mismo, el Ministerio Coordinador de la Producción del Ecuador - MCPEC (2020), tiene como resultado que las Mipymes están dedicadas a satisfacer la demanda interna y externa por esta razón en la actualidad representan el 19\% del total de productos tradicionales y no petroleros exportados, de allí que el desarrollo de estás tiene un proceso lento, que difiere de la gran empresa puesto que su capitalización comúnmente proviene de recursos propios, prestamos en instituciones financieras, y otros en un mínimo porcentaje de acceso y emisión de acciones, lo que incide en el estímulo al desarrollo productivo y a la comercialización y al pago de tributos.

Debido a la situación crítica que está atravesando el mundo, nuestro país y la región, por la pandemia del covit 19 y el confinamiento, las pequeñas y medianas empresas han tenido que optar por nuevas medidas para un desarrollo productivo, estrategias que permitan impulsar nuevas formas de emprendimiento, que están vinculadas al comercio electrónico, "el proceso de producción, distribución, comercialización, venta, transferencia o entrega de bienes y servicios, o la transmisión de fondos o datos, por medios electrónicos", es una manera de comprar y vender productos o servicios, a través del uso de TIC principalmente, gracias a la masificación del uso del internet, que en el caso concreto de la provincia del Azuay, abarca a más de la mitad de la población, de entre las principales transacciones realizadas, según Cámara Ecuatoriana de Comercio Electrónico -CECE (2020), están productos de primera necesidad, comida, bebidas, El contenido gratuito de webinars (clases 
en línea) es el gancho de este sitio, sumado en una mínima parte a artículos electrónicos, entre otros, permitieron ingresar a las arcas fiscales algo de impuestos.

En esta orientación, la información que aportó al estudio en referencia permitió establecer que, mediante el nuevo régimen impositivo para las microempresas, creado en la Ley de Simplificación Tributaria (2019), ya tiene las reglas para su aplicación. El Servicio de Rentas Internas (SRI) emitió una resolución sobre el catastro y obligaciones de estos contribuyentes. El documento fue expedido el 13 de febrero y da cumplimiento a una disposición transitoria de la ley que fijó un plazo de 20 días, desde la vigencia de la norma, para que el SRI efectuara una actualización de oficio del Registro Único de Contribuyentes (RUC) a las microempresas. Según el reglamento del Código de la Producción, son microempresas aquellos negocios con ventas o ingresos brutos anuales iguales o menores a USD \$ 300000 . La actualización del catastro del RUC se hizo sin comunicación previa por parte de la autoridad.

Es conveniente destacar que el análisis de la presente investigación, tuvo como objetivo primordial realizar un análisis de efectos tributarios en las Mipymes y el impacto del contenido de la Ley de simplificación y progresividad tributaria (2020) que tendrá en los contribuyentes, por un lado, para los microempresarios, la simplificación en la tramitología en la presentación de sus obligaciones, pero sin duda el trámite será semestral, como manda la ley, la inclusión en el catastro no será permanente, este tiempo no podrá ser mayor a cinco ejercicios fiscales, sin embargo los encuestados sostuvieron que habrá complicaciones, por cuanto el esquema planteado para calcular el impuesto a la renta, que no contempla costos ni gastos, podría resultar perjudicial para aquellos negocios que generan altos egresos por su operación y que anteriormente podían deducir del impuesto, por cuanto se tributará el 2\% sobre los ingresos brutos cuando se desconoce si al final del ejercicio habrá pérdidas o ganancias.

\section{Resultados.}

Las Mipymes, que representan el 99\% del total de empresas, que se pueden encontrar oportunidades para impulsar el desarrollo del país. Si el sector cuenta con los elementos para, no sólo mantenerse, sino crecer, contribuirán de manera importante a la economía. Teniendo en cuenta que existen varios casos fortuitos por las cuales las Mipymes en el país, pueden verse afectadas económica y socialmente, con la llegada de una pandemia "COVID-19", que inicio el año pasado y afecta el sistema económico de todo el mundo, las Mipymes se han visto cruelmente afectadas por este nuevo reto que será enfrentar la situación actual y buscar mecanismos eficientes de reactivación económica.

A lo largo de esta investigación, podemos alegar que dentro de los factores de éxito están: la constancia y la perseverancia. ya que las personas proactivas persisten en sus objetivos y no 
miran hacia atrás bajo ninguna circunstancia. Si bien es cierto, la constancia es importante, pero también hay que darle gran importancia a la formación y a la capacitación para lograr un alto conocimiento de lo que se piensa emprender. Este aspecto se juega un papel clave en el desenvolvimiento y sostenibilidad de las Mipymes debido a que al mantener un amplio conocimiento de estrategias y relaciones interpersonales dichas empresas no se verán fracasadas al enfrentar situaciones críticas y quizás no planificadas. Es por ello que de acuerdo al presente proyecto se pretende realizar un análisis, mediante información recogida a profesionales vinculados en el país con la Mipymes, por intermedio de la investigación que busca conocer el accionar y requerimientos que tienen las micro, pequeñas y medianas empresas y los emprendedores, con respecto a la aplicación de la Ley Orgánica de simplificación y Progresividad Tributaria, emitido por el Ministerio de Economía y Finanzas que está rigiendo especialmente a las microempresas y los emprendimientos.

Para el procesamiento y análisis de la información de los actores o participantes del presente trabajo de investigación, para el caso de los cuestionarios, se recurrió para la digitalización de la información en una plantilla en hoja electrónica Excel de diseñado exclusivo para el caso; de esta manera en una base de datos, se realizó un respaldo del archivo y con la ayuda del software libre SPSS, versión 26.0, se realizó el tratamiento estadístico contrastando los resultados. La interpretación de los resultados estadísticos fue un elemento crucial para la formulación del análisis. La tabulación e interpretación de los cuestionarios dirigidos a profesionales Contadores de las Mipymes, se detalla conforme se desprende en el siguiente gráfico.

Gráfico $\mathbf{N}^{\circ} 1$ ¿La ley de simplificación y progresividad tributaria 2020, se encuentra en correspondencia con las directrices de las políticas estratégicas necesarias del Gobierno?

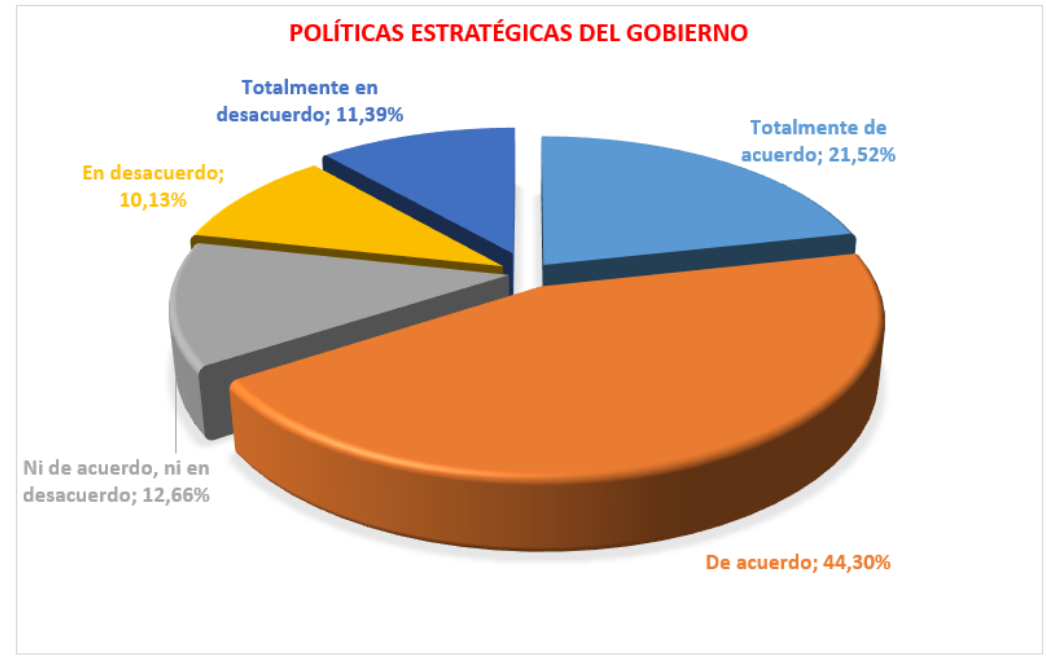

Fuente: Investigación propia (2020).

Elaborado: Grupo Investigador. 
Los resultados evidencian porcentualmente que de los actores encuestados el 44\%,30\% estuvo de acuerdo La ley de simplificación y progresividad tributaria (2019), se encuentra en correspondencia con las directrices de las políticas estratégicas necesarias del gobierno, el 21,52\% están totalmente de acuerdo, al unir ambas tendencias representan tenemos el 65,82, quienes señalan todo gobierno debe implementar políticas estratégicas que coadyuven a la economía nacional y para ello es necesaria la expedición y aplicación de normas que regulen todos sus sectores productivos. Para ello debe contar con información estadística que le permita cuantificar la actividad económica productiva, por lo tanto, esta ley es una de las políticas estratégicas del actual gobierno. El 12,66\% expresan que no están ni de acuerdo ni en desacuerdo, mientras que el 10,13, está en desacuerdo y el 11,39\% se pronunció estar en total desacuerdo, al unir estas tres tendencias se tiene un porcentaje total 34,18 , esto es indicativo que es no están de acuerdo con las políticas del actual gobierno.

Gráfico $\mathbf{N}^{\circ} 2$ ¿Cómo ve el régimen simplificado para microempresas?

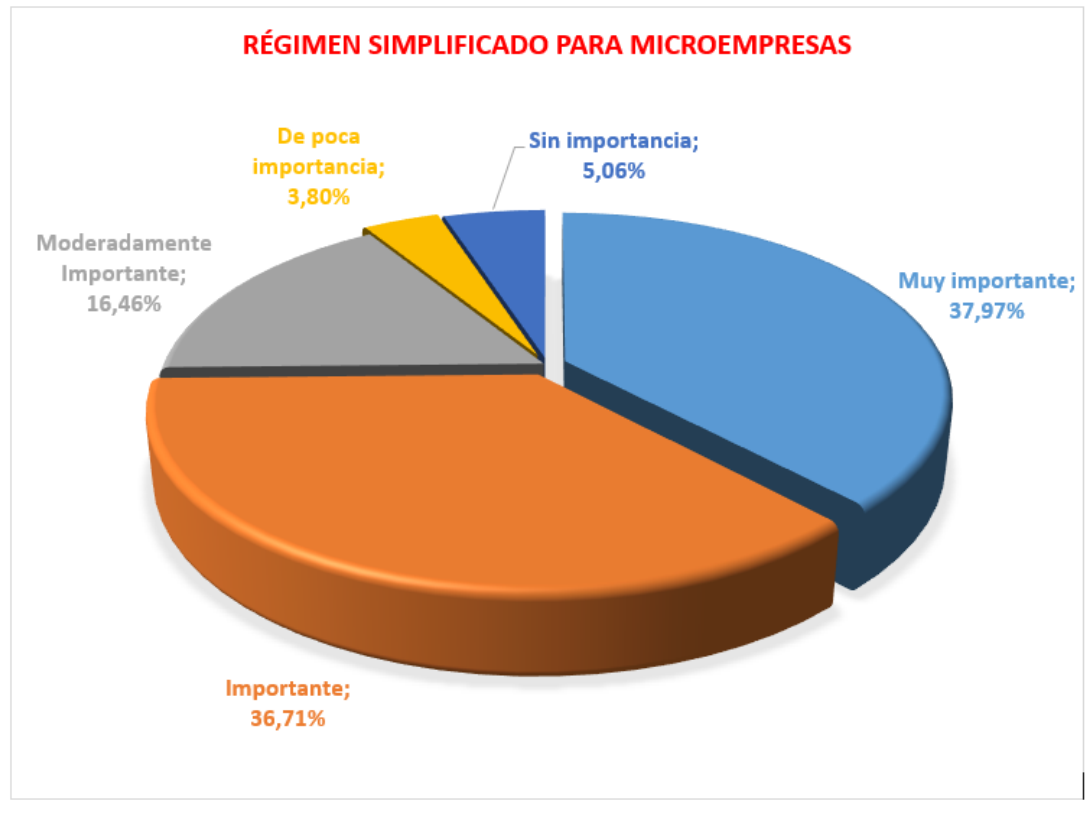

Fuente: Investigación propia (2020).

Elaborado: Grupo Investigado.

Los resultados evidencian porcentualmente, según los actores encuestados que el régimen simplificado para microempresas es muy importante, en un $37,97 \%$, importante en un $36,71 \%$, moderadamente importante el $16,46 \%$, al unir estas tres tendencias tenemos el 91,46\%, por tanto La promulgación de la Ley orgánica de simplificación y Progresividad Tributaria (2019), viene a reordenar el segmento tributario en el sector micro empresarial al determinar sus obligaciones y ordenar un control contable de sus actividades, con lo cual 
tanto el microempresario como el Emprendedor podrán contar a futuro con información financiera confiable que le permitirá una mejor toma de decisiones.

Por otra parte, encontramos la opción, sin importancia por un lado y por otro de poca importancia, esto es indicativo que es necesario revisar régimen simplificado para microempresas que actualmente, se está implementando, con la finalidad de promover un modelo de cultura microempresarial emprendedora para formar ciudadanos económicamente activos, con la finalidad de aumentar su capital humano y tributario.

Gráfico $\mathbf{N}^{\circ} 3$ Considera usted que, en las MIPYMES, existe una política para atender la simplificación y progresividad tributaria, que permita reordenar la actividad tributaria financiera.

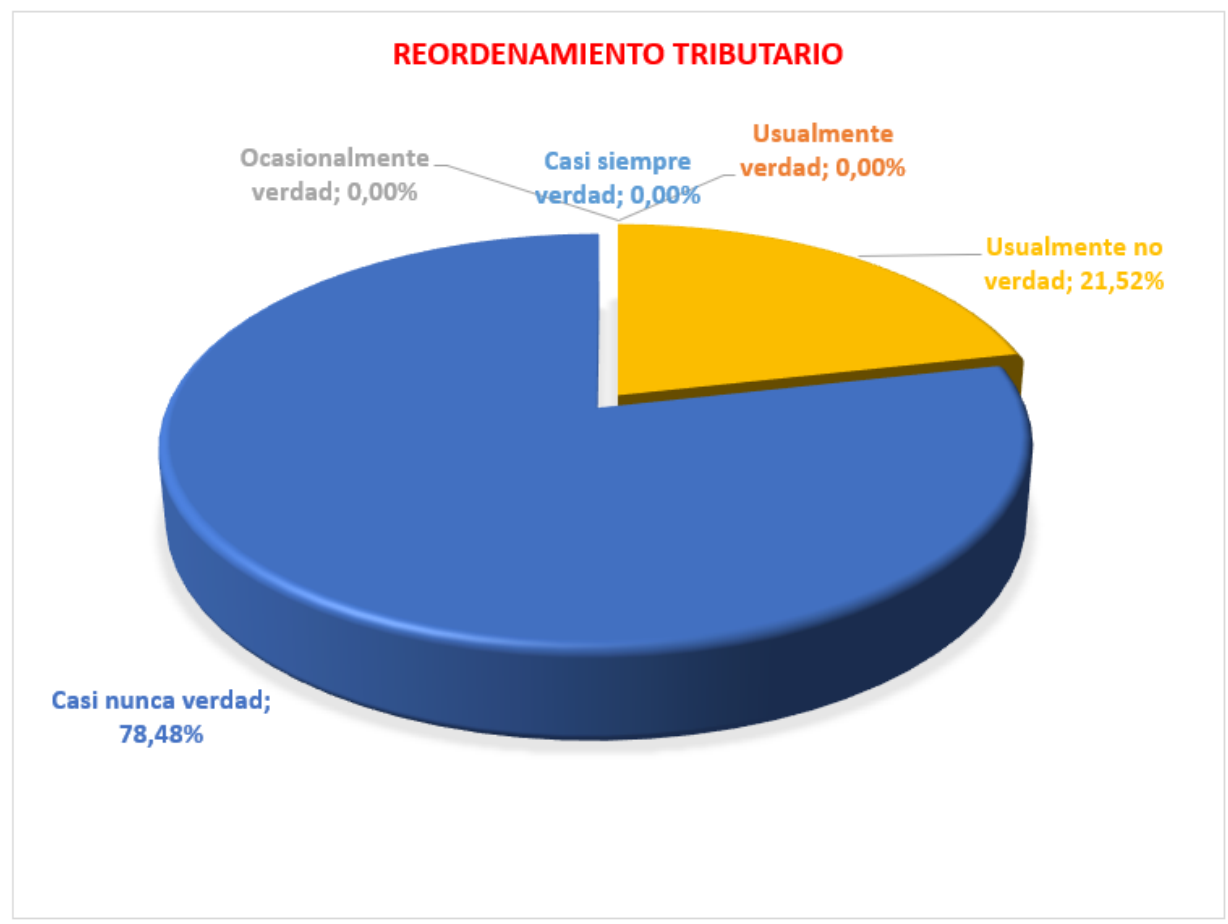

Fuente: Investigación propia (2020).

Elaborado: Grupo Investigador.

El análisis indica, que de acuerdo al grafico el 78,48, optaron por la opción casi nunca verdad y el $21,52 \%$ por usualmente no verdad, con respecto a la pregunta referente a que, en las MIPYMES, existe una política para atender la simplificación y progresividad tributaria, que permita reordenar la actividad tributaria financiera, al unir estas dos preferencias tenemos un $100 \%$ que consideró que en las Mipymes casi nunca se implementan y se aplican políticas tributarias, por lo tanto con la Ley de simplificación y Progresividad Tributaria, se viene a reordenar el aspecto tributario. 
Gráfico $\mathbf{N}^{\circ} 4$ En el régimen simplificado: ¿Cuáles de los siguientes enunciados considera reordenar el aspecto tributario financiero?

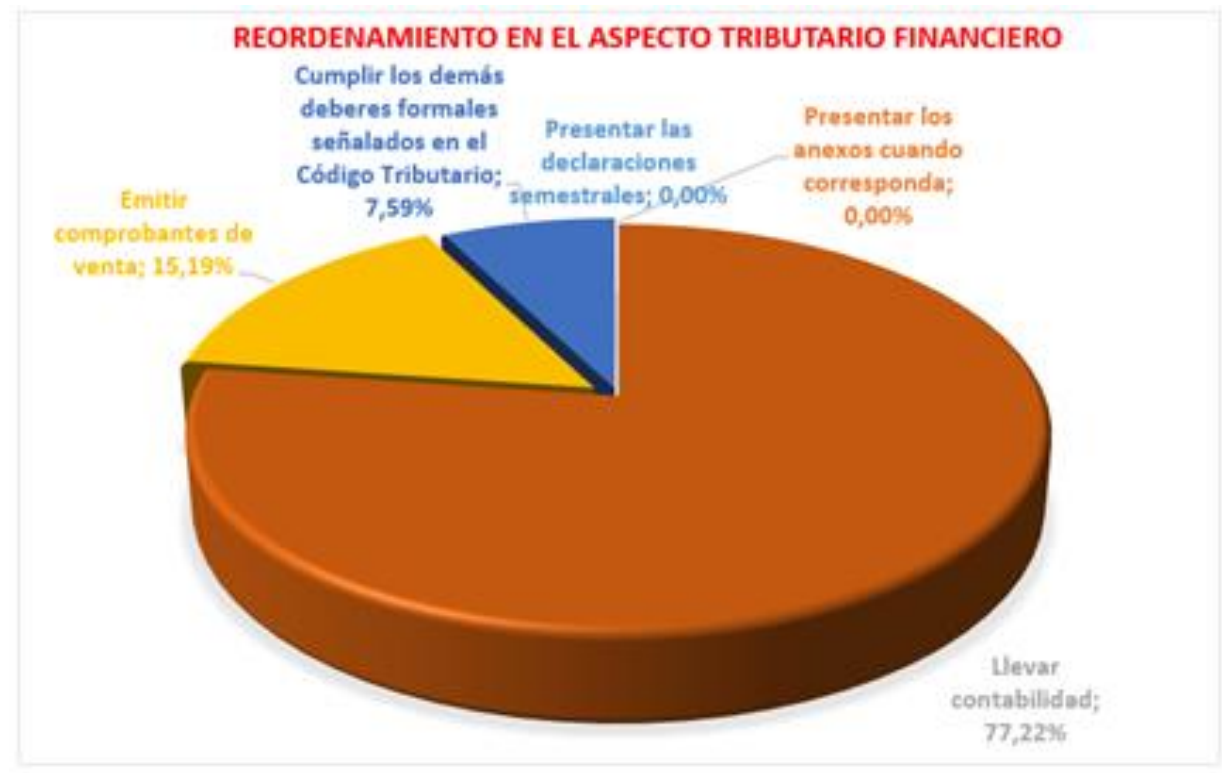

Fuente: Investigación propia.

Elaborado: Grupo Investigador.

Los resultados evidencian que dentro régimen simplificado para reordenar el aspecto tributario financiero especialmente de las microempresas el 77,22\%, es la opción llevar contabilidad, toda vez que las Mipymes, generan la mayor cantidad de ingresos, constituyen el mayor porcentaje de fuentes de trabajo, por lo tanto la implementación de un régimen simplificado de cumplimiento tributario, les viene a reordenar directamente el aspecto tributario y financiero, y a través de la obligación de llevar contabilidad vienen a generar otro rubro de ingresos a los trabajadores por el pago de la participación del 15\% de utilidades. Así mismo el 15,19\% sostienen que permitirá emitir comprobantes de venta, puesto que la facturación física es un instrumento que permite emitir comprobantes de venta autorizados por el SRI. Sirve para respaldar las transacciones que efectúen los sujetes pasivos, llamados contribuyentes, ya sea por la transferencia de bienes o por la prestación de servicios o la realización de transacciones gravadas con tributos.

Igualmente, el 7,59\% de actores encuestados indican que se debe ccumplir los demás deberes formales señalados en el Código Tributario, en donde la contabilidad deberá ser llevada bajo la responsabilidad y con la firma de un contador público legalmente autorizado e inscrito en el Registro Único de Contribuyentes (RUC), por el sistema de partida doble, en español y en dólares y cumplir con las correspondientes declaraciones y anexos, que deben ser presentados por internet. 
Gráfico $\mathbf{N}^{\circ} 5$ Dentro de la ley de régimen de simplificación y progresividad tributaria se considera sujetos tributables, señale las siguientes opciones.

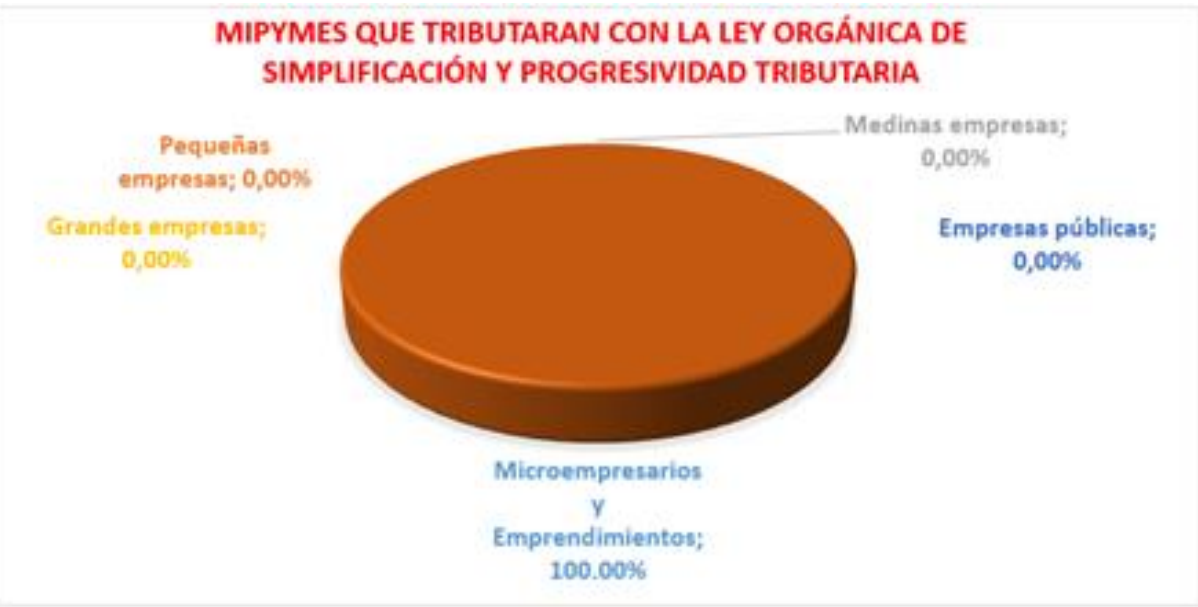

Fuente: Investigación propia (2020).

Elaborado: Grupo Investigador.

La información recogida permite determinar que las microempresas y emprendimientos, en el $100 \%$, dentro de la ley de régimen de simplificación y progresividad tributaria se considera sujetos tributables, al respecto el artículo 97.22, en la parte pertinente manifiesta que la ttarifa del impuesto a la renta, los contribuyentes determinarán el impuesto a la renta aplicando la tarifa del dos por ciento (2\%) sobre los ingresos brutos del respectivo ejercicio fiscal exclusivamente respecto de aquellos ingresos provenientes de la actividad empresarial. Los ingresos percibidos por las microempresas por fuentes distintas a la actividad empresarial se sujetarán al régimen general del impuesto a la renta y será de aplicación obligatoria para las microempresas.

Gráfico $\mathbf{N}^{\circ} 6$ ¿De qué manera impactará el régimen simplificación y progresividad tributaria en las Mipymes?

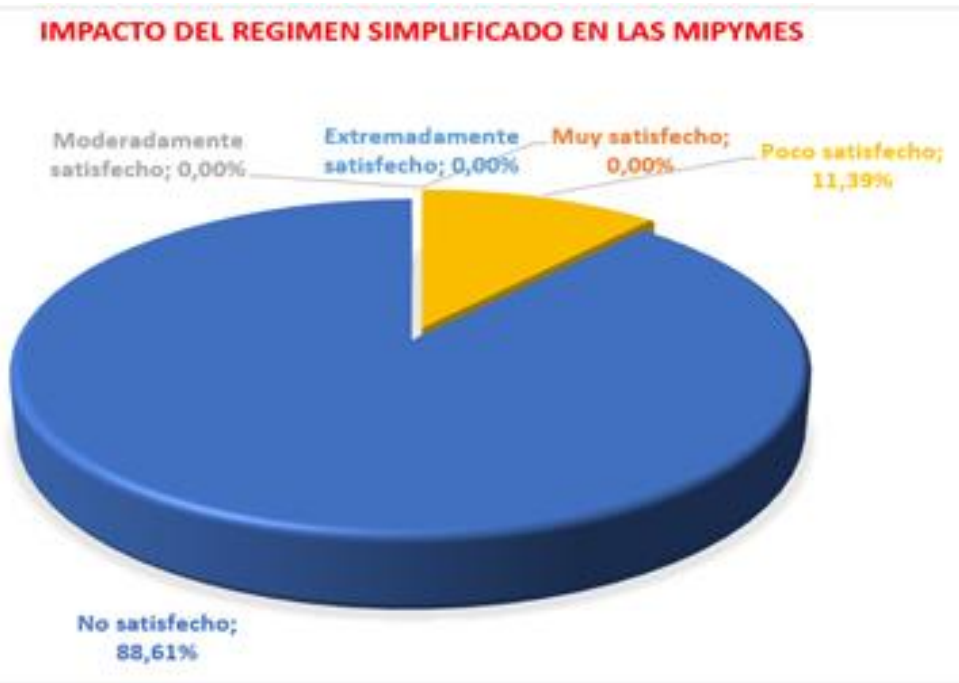

Fuente: Investigación propia.

Elaborado: Grupo Investigador. 
Los resultados evidencian, que el 88,61\%, no están satisfechos, y el 11,39\% están pocos satisfechos, con respecto al impacto que tendrá el régimen simplificación y progresividad tributaria en las Mipymes, al unir estas dos tendencias se tiene un porcentaje total del $100,00 \%$, esto implica manifestar que el impacto que tendrá en los contribuyentes va ser significativo, si bien es verdad los sujetos pasivos van a realizar declaraciones semestrales de IVA, sin embargo esto afectará toda vez que implica el pago del $2 \%$ del impuesto a la renta sobre los ingresos brutos, sin considerar costos y gastos, de allí que en el ejercicio económico del año 2019, tributaron el 22\% sobre las ganancias netas

Gráfico $\mathbf{N}^{\circ} 7$ ¿Cuáles de los siguientes beneficios de la reciente aprobación de las Sociedades Anónimas Simplificadas SAS, considera usted la más importante?

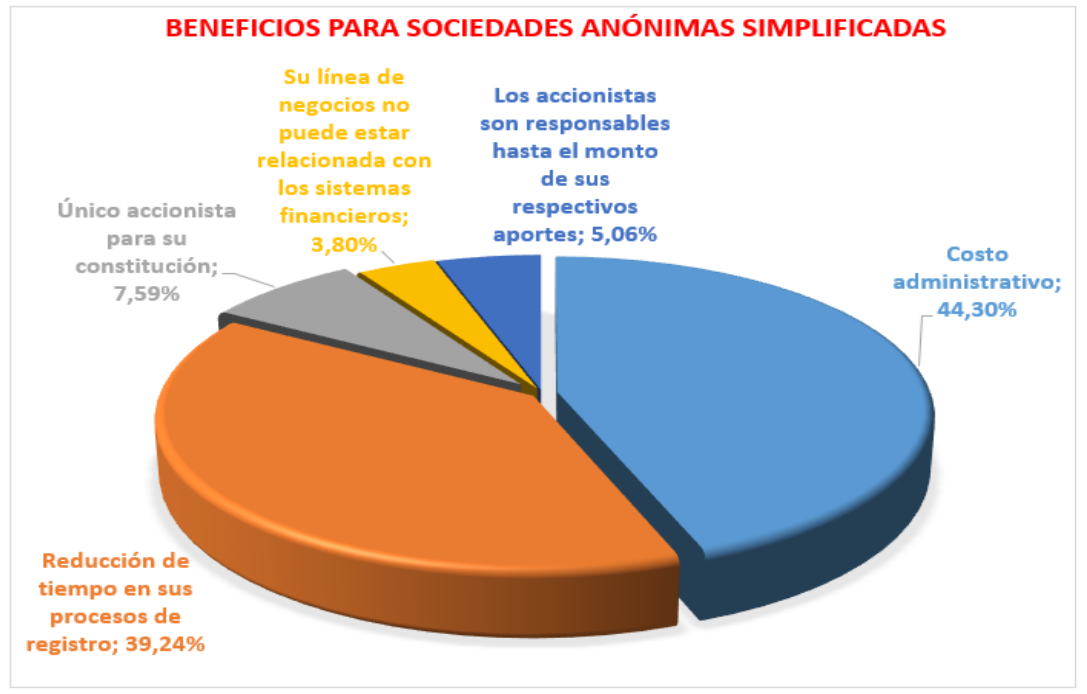

Fuente: Investigación propia.

Elaborado: Grupo Investigador.

Los profesionales encuestados manifiestan en su mayoría, esto es el 44,30\%, sostuvieron que corresponde a los costos administrativos, entre uno de los beneficios de la reciente aprobación de las Sociedades Anónimas Simplificadas SAS, así mismo el 39,24\%, sostienen que la reducción de tiempos en sus procesos de registro, el 7,59\% manifestaron el hecho de ser los únicos accionistas para su constitución, el 5,06\% sostienen que los accionistas son responsables hasta por el monto de sus respectivos aportes, y por último el 3,80\% sostienen que su línea de negocio, no pueden estar relacionados con los sistemas financieros.

La promulgación de la Ley de simplificación y Progresividad Tributaria, es la antesala del control tributario a las empresas que se vayan a crear bajo la Ley de Emprendimiento e Innovación (2020), que tiene como objeto fortalecer el régimen tributario ecuatoriano y la política fiscal, fomentar el emprendimiento y la actividad de exportación en el país así como 
ISSN: 2600-5859

Vol. 3, $\mathrm{N}^{\circ} 2.2$, p. 111-131, junio, 2020

instaurar un régimen tributario simplificado que facilite a la ciudadanía el cumplimiento de sus obligaciones tributarias y deberes formales; todo lo cual está enfocado en precautelar un sistema tributario con sostenibilidad fiscal, y por otra parte la creación de las empresas de Acciones simplificadas SAS, que constan en el mismo documento. Estas dos nuevas leyes están relacionadas, por lo que amerita un estudio de ambas por parte de los Contadores, con lo cual pueden generar una nueva fuente de ingresos con la asesoría y aplicación correcta de las normativas. La Sociedad por Acciones Simplificada (SAS) es la innovación más importante del Derecho Societario Ecuatoriano en décadas y es necesario estar preparados para su entrada en vigencia con el fin de facilitar al emprendedor en la realización de sus actividades mercantiles.

\section{Discusión.}

Como es lógico, el análisis indicó que, dentro del grupo de las Mipymes, están los microempresarios, pequeños empresarios y emprendedores, al analizar profundamente el contexto de la Ley Orgánica de Simplificación y Progresividad Tributaria, aplicable a este sector, al margen de conocer la utilidad que pueda tener, las mismas tienen problemas desde el año anterior, por cuanto resultaron las más perjudicadas como efecto de las paralización de octubre, por el paro que existió de los transportistas e indígenas y de los sectores sociales, en donde, ya se notó la disminución de sus ingresos, ahora con la nueva ley tributaria, se determina imposiciones, que con el carácter de impositiva, sumada a este época de crisis económica, por la pandemia del covit 19, a nivel no solo nacional, si no mundial, se agravó la situación económica, de allí que si no fuera por la existencia de la moneda del dólar, que no es nuestra, la economía Ecuatoriana se hubiese derrumbado ostensiblemente.

No obstante, partamos del hecho de que los microempresarios dejan de ser agentes de retención, y las declaraciones pasan a ser semestrales, si en la realidad a las microempresas le ha hecho mucha falta los ingresos del mes a mes, los recursos económicos que se requiere para poder cumplir con las obligaciones tributarias, ahora que ira a pasar cuando se habla de que tiene que acumular semestralmente aquellos recursos que necesitaran para cubrir la obligación semestral del cruce del IVA, cuando lleguemos a enero del 2021, es de anotar que si los pequeños empresarios tuvieron disminución en los ingresos en octubre, ahora sumada a la pandemia y la emergencia sanitaria, desde mediados de marzo, abril, mayo, y recién en junio o mediados del mes se reactivaría sus actividades, lo que nos indica que si en quince días existió desfases financieros con este periodo de confinamiento, la repercusión se ahonda aún más, el impacto es pertinaz, por cuanto a la Administración Tributaria le es indiferente, si se pierde, se destruya o desaparezca el negocio, se piensa que para el Servicio de Rentas Internas es importante la recaudación de ese $2 \%$ que les imponen, sin interesarles, cual es el resultado, por ello consideramos que es una imposición retrograda, que en lugar de aplicar el 
procedimiento, de ayuda que el Estado debería preocuparse por la microempresa, estos tributos significarían un golpe duro a su economía.

Con esta ley, el sujeto pasivo microempresarial es objeto de retención, es decir ya paga un anticipo de impuesto a la renta, en todas sus ventas, ya sea de bienes o servicios, le van a retener si es bienes en unos casos el $1 \%$ y en otros el $1,75 \%$ y si es servicios el $2 \%$ o el $2,75 \%$, a ello sumado el $2 \%$ que tiene que tributar ya en enero del 2021, según el criterio de la administración tributaria es que no se considere todo lo que le hayan retenido, primero tiene que pagar y luego hacer la petición de devolución, con ello le resta liquidez a la microempresa de una manera indolente, consecuentemente esto va a tener impacto negativo, con mayor repercusión en la actualidad en la que se encuentran, razón especial para el cierre de los microempresas, el despido de los trabajadores, por tanto el impacto en la economía nacional será muy fuerte.

\section{Conclusiones.}

- A continuación, se exponen las principales conclusiones, integrando los resultados de las encuestas, y la técnica de la observación, en tal sentido se señala a continuación:

- Las medianas y grandes empresas para la determinación impositiva continuaran bajo el régimen general, considerando sobre las utilidades brutas el 15\% de participación para sus trabajadores, y el impuesto a la renta del $25 \%$ sobre las ganancias netas, antes formulario 101, hoy formulario (1021), continuaran actuando como agentes de retención y realizando su declaración mensualmente tanto del impuesto al valor agregado IVA en el formulario antes 104, hoy ( código 2011), como de las retenciones en la fuente formulario antes 103, hoy (código 1031), además de los consumos especiales (ICE), así también los correspondientes anexos transaccional simplificado (ATS), que en forma mensual se presentan y las demás obligaciones tributarias correspondientes de acuerdo a las fechas que corresponda.

- Según, el Art. 10.17, la Ley de Régimen Tributario Interno -LRTI (2004). Para el cálculo del impuesto a la renta, durante el plazo de 5 años, las micro, pequeñas y medianas empresas tendrán derecho a la deducción del 100\% adicional de los gastos incurridos en los siguientes rubros: 1.- Capacitación técnica dirigida a investigación, desarrollo e innovación tecnológica, que mejore la productividad, y que el beneficio no supere el $5 \%$ del valor de los gastos efectuados por conceptos de sueldos y salarios del año en que se aplique el beneficio; 2. Gastos en la mejora de la productividad a través de las siguientes actividades: asistencia técnica en desarrollo de productos mediante estudios y análisis de mercado y competitividad; asistencia tecnológica a través de contrataciones de servicios profesionales para diseño de procesos, productos, adaptación e implementación de procesos, de diseño de empaques, de desarrollo de software especializado y otros servicios de desarrollo empresarial que serán especificados en el Reglamento de esta ley, y que el beneficio no superen el 5\% 
de las ventas; y, 3. Gastos de viaje, estadía y promoción comercial para el acceso a mercados internacionales, tales como ruedas de negocios, participación en ferias internacionales, entre otros costos o gastos de similar naturaleza, y que el beneficio no supere el $50 \%$ del valor total de los costos y gastos destinados a la promoción y publicidad. Para los exportadores habituales y el sector de turismo receptivo, este beneficio será hasta por el $100 \%$ del valor total de los costos y gastos destinados a la promoción y publicidad.

- El análisis permitió determinar que para el caso de las Mipymes, especialmente en donde están las medianas empresas se crea una contribución única y temporal por tres años, para quienes hayan obtenido ingresos gravados en el ejercicio fiscal 2018 por al menos USD \$1 millón, la tarifa anual será de entre el 0,10\% y el 0,20\%, considerando el monto de dichos ingresos, esta contribución se pagará en marzo de los años 2020, 2021 y 2022, sin que en ningún caso sea superior a la cuarta parte del impuesto a la renta causado en el ejercicio fiscal 2018, sobre estos tributos se puede solicitar facilidades de pago hasta por tres meses.

- De acuerdo con el régimen impositivo para microempresas, se encuentran dentro del mismo, las microempresas, pequeños comerciantes, emprendedores, además las personas naturales obligadas y no a llevar contabilidad y las sociedades que hayan tenido ingresos brutos al año inmediato anterior iguales o menores a $\$ 300.000,00$.

- Por otra parte, no están en este régimen aquellos contribuyentes que obtengan ingresos por contratos de construcción, ingresos por actividades de urbanización, lotización, transferencia de inmuebles, los servicios profesionales, ocupación liberal, personas que tengan relación de dependencia, aquellos que tengan rentas de capital, es decir los tenedores de acciones, y los sujetos pasivos que estén considerados dentro del régimen impositivo simplificado ecuatoriano (RISE).

- Co respecto a la inclusión, la misma será de oficio, no se podrá solicitar al SRI que se incluya, esto queda a potestad de la administración tributaria, para el caso de personas naturales con apertura de RUC o reinicio del RUC, podrán solicitar la inclusión al nuevo régimen y tendrán efecto al instante. En personas naturales con RUC existente y que realicen actualización, podrán solicitar la inclusión al nuevo régimen y tendrá efecto al siguiente ejercicio fiscal, en sociedades la inclusión será de oficio.

- De igual forma para la exclusión, los contribuyentes tuvieron el plazo de 30 días hábiles contados desde el 13 de febrero del 2020, por el estado de emergencia sanitaria que vive el país, no se necesita enviar por el QUIPUX, solo por correo electrónico, de acuerdo a su jurisdicción.

- Así mismo, la permanencia será mientras dure su condición de microempresa, tendrá efecto al siguiente ejercicio económico, máximos cinco años fiscales.

- Igualmente, los deberes formales de los contribuyentes consisten en emitir comprobantes de venta, llevar contabilidad cuando corresponda, presentar las 
declaraciones respectivas, presentar los anexos cuando corresponda, cumplir los demás deberes formales señalados en el código tributario.

- De igual forma en el caso de las retenciones, no serán agentes de retención no de renta ni de IVA, salvo en los siguientes casos, por pagos a no residentes, importación de servicios, enajenación de acciones, distribución de dividendos, pagos a los empleados en relación de dependencia, es conveniente destacar que, aunque el microempresario no será agente de retención, pero si debe recibir retenciones, esta retención recibida serán créditos tributarios en renta e IVA cuando correspondan.

- El análisis indico que para el caso de las declaraciones del 2011 del IVA, así realice retenciones de IVA, será semestrales, del 1031 será mensual únicamente en los meses que esté obligado a retener, la declaración del ICE será también semestral, los anexos transaccionales ATS, se espera sea semestral, pero ahora como está la normativa es mensual, (NAC $\mathrm{N}^{\circ} 12$ ), sin embargo sea mensual o semestral hay que cruzar con el ATS, así también el anexo del ICE se espera sea semestral, en cuanto a la declaración de renta es anual del $2 \%$ sobre los ingresos brutos, así lo determina el articulo 97.22 y 97.23 de la LRTI., se espera que esto sea sobre los ingresos netos ya restados de las devoluciones o notas de crédito y los descuentos.

- La información permitió determinar que la declaración de las retenciones en la fuente no debe ser como obligación mensual, se espera que el cálculo del $2 \%$ no sea sobre los ingresos brutos, sino sobre los ingresos netos, ya considerados las notas de créditos y descuentos, así mismo el formulario de impuesto a la renta sea actualizado para el siguiente ejercicio fiscal, donde consten los cálculos para el $2 \%$.

- En cuanto a la administración tributaria definirá de oficio quienes serán agentes de retención y quienes no, el ser obligado a llevar contabilidad, ya no está ligado con las retenciones, en cuanto a la presentación del servicio diverso la actual retención es del $2,75 \%$, se conmina al fisco que se retenga solo el $2 \%$ por pertenecer al nuevo régimen de microempresas.

- Por ultimo como recomendación podemos anotar que, aunque este impuesto se paga sobre los ingresos brutos, se debe seguir teniendo bien sustentados todos los gastos del giro del negocio, es importante considerar que no resultaría necesario lo correspondiente a gastos personales, salvo si tuvieran otros ingresos, como por ejemplo relación de dependencia, de igual manera se recomienda poner una leyenda a los comprobantes de venta "Régimen Impositivo Microempresarial", además el SRI deberá emitir el reglamento de aplicación a la Ley Orgánica de Simplificación y progresividad tributaria.

- Otro aspecto corresponde a la sociedad por acciones simplificada (SAS), los empresarios pueden precisar las reglas que van a regir el funcionamiento de la sociedad. De allí sería posible contar con estatutos flexibles que se adapten a las condiciones y a los requerimientos de cada empresario, no obstante, la creación de estas empresas es más factible. Una SAS se puede establecer mediante documento privado, lo cual le ahorra a la empresa tiempo y dinero. $\cdot$ La responsabilidad de sus socios se limita a sus aportes. La empresa puede beneficiarse de la limitación de la responsabilidad de sus socios o accionistas, sin tener que tener la ardua tarea de conformar una organización y estructura de una sociedad anónima. 


\section{Referencias bibliográficas.}

Arias, F. (2016). El Proyecto de Investigación: Introducción a la metodología científica. ( $7^{\text {a }}$ Edición), Caracas - Venezuela. Editorial El pasillo, C.A.

Asamblea Constituyente. (2008). Constitución de la República del Ecuador. Montecristi: Asamblea Constituyente, Gaceta oficial No 449 del 20 de octubre del 2008.

Cámara Ecuatoriana de Comercio Electrónico -CECE (2020), Proyectamos crecimiento de 15 veces más de lo habitual, recuperado de: https://www.eluniverso.com/noticias/2020/04/06/nota/7805850/proyectamoscrecimiento-15-veces-mas-habitual

Cañadas, I. y Sánchez-Bruno, A. (1998). Categorías de respuestas en escalas tipo Likert. Psicothema, 10(3), 623-631.

Código Orgánico de la Producción, comercio e inversión, COPCI, , (2010), Esta Ley fue publicada en el Suplemento del Registro Oficial N³ 351, del 29 de diciembre del 2010.

Código tributario, extraído el 30 de abril del 2020 de: https://www.quito.gob.ec/documents/Portal_tributario/Normativa/Ley/CODIGO_T RIBUTARIO_ACT.pdf

Hernández Sampieri, R., Fernández-Collado, C., \& Baptista Lucio, P. (2010). Metodología de la Investigación (Quinta Edición). México: Panamericana Formas e Impresos S.A., pág. 51.

Ley de régimen tributario interno, LRTI, (2004), Esta Ley fue publicada en el Suplemento del Registro Oficial N 463, del 17 de noviembre del 2004.

Ley Orgánica de Emprendimiento e Innovación, (2020), Esta Ley fue publicada en el Suplemento del Registro Oficial $N^{\circ}$ 151, del 28 de febrero del 2020.

Ley Orgánica de Simplificación y Progresividad Tributaria, (2019), Esta Ley fue publicada en el Suplemento del Registro Oficial N 111, del 31 de diciembre del 2019.

Ministerio Coordinador de la Producción del Ecuador-MCPEC (2017). Recuperado de https://www.google.com.ec/search?q=Ministerio+coordinador+de+la+ producci\%C3\%B3n\&oq=Ministerio+coordinador+de+la+producci\%C3\%B3n\&aqs $=$ chrome..69i57j015.15231j0j8\&sourceid=chrome\&ie=UTF-8.

Mersan, Carlos A. "Derecho Tributario", Octava edición. Editora Litocolor. Asunción, 1997. p. 26

Servicio de Rentas Internas -SRI (31/03/2020). Normas para el regimen impositivo para microempresas, Obtenido de Servicio de Rentas Internas: https://nmslaw.com.ec/sri-expide-normas-regimen-impositivo-microempresas/

SENPLADES. (2017). Plan Nacional para el Buen Vivir 2017-2021. Quito: SENPLADES, Gaceta oficial No 681 del 13 de julio del 2017. 


\section{PARA CITAR EL ARTÍCULO INDEXADO.}

Becerra Molina, E., Calle Masache, O., Banegas Peña, T., \& Espinoza Pillaga, H. (2020). Análisis de efectos tributarios en las Mipymes. Una perspectiva e impacto del contenido de la Ley de simplificación y progresividad tributaria 2020. ConcienciaDigital, 3(2.2), 111-131. https://doi.org/10.33262/concienciadigital.v3i2.2.1249

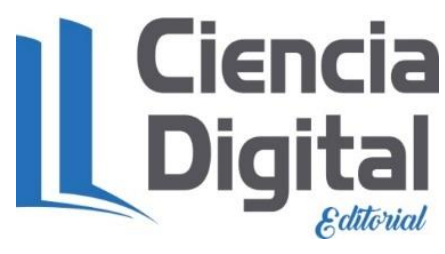

El artículo que se publica es de exclusiva responsabilidad de los autores y no necesariamente reflejan el pensamiento de la Revista Conciencia Digital.

El artículo queda en propiedad de la revista y, por tanto, su publicación parcial y/o total en otro medio tiene que ser autorizado por el director de la Revista Conciencia Digital.
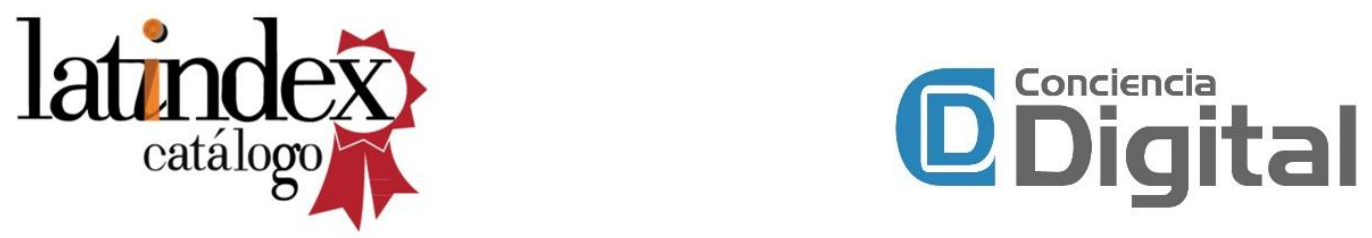